\title{
Assessment of passive drag in swimming by numerical simulation and analytical procedure
}

\author{
Tiago M. Barbosa, Rui Ramos, António J. Silva \& Daniel A. Marinho
}

To cite this article: Tiago M. Barbosa, Rui Ramos, António J. Silva \& Daniel A. Marinho (2017):

Assessment of passive drag in swimming by numerical simulation and analytical procedure, Journal of Sports Sciences, DOI: 10.1080/02640414.2017.1321774

To link to this article: http://dx.doi.org/10.1080/02640414.2017.1321774

册 Published online: 28 Apr 2017.

Submit your article to this journal $\widetilde{ }$

Џ Article views: 2

Q View related articles $\circlearrowright$

View Crossmark data $₫$ 


\title{
Assessment of passive drag in swimming by numerical simulation and analytical procedure
}

\author{
Tiago M. Barbosa ${ }^{a, b, c}$, Rui Ramos ${ }^{b, d}$, António J. Silva ${ }^{b, e}$ and Daniel A. Marinho ${ }^{b, d}$ \\ aPhysical Education \& Sports Science Academic Group, National Institute of Education, Nanyang Technological University, Singapore; ${ }^{b}$ Research Centre \\ in Sports, Health and Human Development, Vila Real, Portugal; 'Department of Sport Sciences, Polytechnic Institute of Bragança, Bragança, Portugal; \\ 'Department of Sport Sciences, University of Beira Interior, Covilha, Portugal; 'Department of Sport Sciences, University of Trás-os-Montes and Alto \\ Douro, Vila Real, Portugal
}

\section{ABSTRACT}

The aim was to compare the passive drag-gliding underwater by a numerical simulation and an analytical procedure. An Olympic swimmer was scanned by computer tomography and modelled gliding at a 0.75$\mathrm{m}$ depth in the streamlined position. Steady-state computer fluid dynamics (CFD) analyses were performed on Fluent. A set of analytical procedures was selected concurrently. Friction drag $\left(D_{\mathrm{f}}\right)$, pressure drag $\left(D_{\text {pr }}\right)$, total passive drag force $\left(D_{\mathrm{f}+\mathrm{pr}}\right)$ and drag coefficient $\left(C_{\mathrm{D}}\right)$ were computed between 1.3 and $2.5 \mathrm{~m}$ . $\mathrm{s}^{-1}$ by both techniques. $D_{\mathrm{f}+\mathrm{pr}}$ ranged from 45.44 to $144.06 \mathrm{~N}$ with CFD, from 46.03 to $167.06 \mathrm{~N}$ with the analytical procedure (differences: from $1.28 \%$ to $13.77 \%$ ). $C_{D}$ ranged between 0.698 and 0.622 by CFD, 0.657 and 0.644 by analytical procedures (differences: $0.40-6.30 \%$ ). Linear regression models showed a very high association for $D_{f+p r}$ plotted in absolute values $\left(R^{2}=0.98\right)$ and after log-log transformation $\left(R^{2}=0.99\right)$. The $C_{\mathrm{D}}$ also obtained a very high adjustment for both absolute $\left(R^{2}=0.97\right)$ and log-log plots $\left(R^{2}=0.97\right)$. The bias for the $D_{\mathrm{f}+\mathrm{pr}}$ was $8.37 \mathrm{~N}$ and $0.076 \mathrm{~N}$ after logarithmic transformation. $D_{\mathrm{f}}$ represented between $15.97 \%$ and $18.82 \%$ of the $D_{f+p r}$ by the CFD, $14.66 \%$ and $16.21 \%$ by the analytical procedures. Therefore, despite the bias, analytical procedures offer a feasible way of gathering insight on one's hydrodynamics characteristics.
ARTICLE HISTORY

Accepted 10 April 2017

KEYWORDS

Swimming; gliding; drag coefficient; friction drag; pressure drag

\section{Introduction}

Hydrodynamics is one of the main determinants of human performance in the aquatic environment (Barbosa et al., 2010). Research in this field focuses strongly on the effects of the drag force acting upon the participant's body. The drag force is termed "passive" if the participant is being towed or gliding, with no limb actions (Kjendlie \& Stallman, 2008), whereas when the swimmer is propelling themselves, it is referred as "active drag" (Formosa, Sayers, \& Burkett, 2014).

To learn about swimmer's passive drag, literature reports three different approaches (Barbosa et al., 2015; Takagi, Nakashima, Sato, Matsuuchi, \& Sanders, 2015): (1) experimental techniques (towing and gliding tests), (2) numerical simulations (computer fluid dynamics [CFD]) and (3) analytical procedures (a set of mathematical models encompassed by Naval Architecture but adapted to human swimming, followed by use of the drag equation). Eventually, researchers started to investigate whether the different approaches would return the same results (i.e., goodness-of-fit), if they were sensitive enough to reflect the same phenomenon or not. It was reported that experimental data tend to overestimate the values in comparison to numerical simulations (Costa et al., 2015). Nevertheless, both CFD and experimental data were dependent on swimming velocity. Earlier on, it was reported that drag force determined by CFD simulation was within $4 \%$ of the experimental data collected in a mannequin, albeit the mannequin's drag was $18 \%$ less than human's drag (Bixler, Pease, \& Fairhurst, 2007). Linear regression models between experimental and analytical procedures showed a high association for passive drag $\left(R^{2}=0.90\right)$ and passive drag coefficient $\left(R^{2}=0.96\right)$ (Barbosa et al., 2015). On average, there was an underestimation by the analytical procedure of $-7.0 \mathrm{~N}$ for the passive drag and an overestimation of 0.127 (dimensionless unit) for the passive drag coefficient. The analytical procedures are a novel approach in assessing swimming. We failed to find in the literature a comparison of analytical procedures with numerical simulations.

Both techniques allow the computation of the partial drag components. Hence, it is also possible to compare its partial contribution to total drag. When gliding fully immersed, the wave drag is considered negligible (Vennell, Pease, \& Wilson, 2006). Hence, the total drag is reduced to the sum of friction drag $\left(D_{\mathrm{f}}\right)$ and pressure drag $\left(D_{\mathrm{pr}}\right)$. For a body gliding fully immersed, other numerical simulations reported contributions by the $D_{\mathrm{pr}}-D_{\mathrm{f}}$ components of $85-15 \%$ (Marinho, Barbosa, Rouboa, \& Silva, 2011) and 75-25\% (Bixler et al., 2007). One analytical model reported the contribution of the $D_{\mathrm{pr}}-D_{\mathrm{f}}$ of $65-35 \%$ wearing a waist-knee swimsuit and $71-29 \%$ in a conventional suit (Mollendorf, Termin, Oppenheim, \& Pendergast, 2004). These contributions seem to vary significantly from the values reported by the numerical simulations. However, in young participants, another analytical model obtained an 
average $D_{\mathrm{pr}}-D_{\mathrm{f}}$ contribution of $86-14 \%$ (Barbosa et al., 2015). Therefore, there are mixed findings on the partial contribution of different components to the total drag.

The aim of this research was to compare the passive drag assessed by numerical simulation and analytical procedures, as well as learning the partial contribution of the friction and pressure components to total drag. It was hypothesised that despite describing the same phenomenon, a bias might exist between both techniques. The pressure drag would display a higher percentage of the total drag.

\section{Methods}

\section{Participants}

One male swimmer who raced regularly short- and middledistance Freestyle events at major competitions, including World Championships and Olympic Games, was recruited. After a briefing explaining the procedures and aims of this research, written consent was provided by the participant. All procedures complied with the Helsinki Declaration and approved by the university ethical committee.

\section{Procedures}

\section{Anthropometrics and inertial parameters}

The body was scanned by computer tomography (CT) (Aquilion 4 Slice, Toshiba, Japan) providing a 3D digital model. CT scans were collected with configuration of V2.04 ER001 ( $2 \mathrm{~mm}$ slice thickness with $1 \mathrm{~mm}$ gap). The transformation of CT scans in nodal coordinates into an appropriate coordinate system was conducted on AnatomicsPro.

\section{Numerical simulation}

The swimmer was modelled gliding underwater at $0.75-\mathrm{m}$ depth in a streamlined position. The boundary conditions of the CFD model were designed representing the geometry and flow conditions of a swim lane $(8.0 \mathrm{~m} \times 2.5 \mathrm{~m} \times 2.0 \mathrm{~m})$. The distances between the swimmer, the front and back surfaces were 2.0 and $3.60 \mathrm{~m}$, respectively. The body surface had roughness parameters of zero. The whole domain was meshed with 900 million cells (hybrid mesh of prisms and pyramids, decreasing the grid node separation in areas of high velocity and pressure gradients).

Steady-state CFD analyses were performed on Fluent (ANSYS, Hanover, USA). This code solves flow problems replacing the Navier-Stokes equations with discretised algebraic expressions (Rouboa, Silva, Leal, Rocha, \& Alves, 2006). Fluent features the finite volume approach, where the equations are integrated over each control volume. The solutions of the governing system equations are given in each square element of the discretised whole domain. To solve the linear system, the code adopts an Algebraic Multi-Grid solver. Being the most accurate in these settings, the segregated solver with the standard k-epsilon turbulence model was selected (Rouboa et al., 2006):

$$
\operatorname{div} V=0
$$

$$
\begin{gathered}
\frac{\partial V}{\partial t} \pm V \cdot \nabla V+\nabla p \pm \nabla\left(v+c_{\mu} \frac{k^{2}}{\varepsilon}\right)\left(\nabla V+\nabla V^{t}\right)=0 \\
\frac{\partial(\rho k)}{\partial t}+\frac{\partial\left(\rho V_{x} k\right)}{\partial x}+\frac{\partial\left(\rho V_{y} k\right)}{\partial y}+\frac{\partial\left(\rho V_{z} k\right)}{\partial z}= \\
\frac{\partial\left(\left(\mu_{\mathrm{t}} / \sigma_{\mathrm{k}}\right)(\partial k / \partial x)\right)}{\partial x}+\frac{\partial\left(\left(\mu_{\mathrm{t}} / \sigma_{\mathrm{k}}\right)(\partial k / \partial y)\right)}{\partial y} \\
+\frac{\partial\left(\left(\mu_{\mathrm{t}} / \sigma_{\mathrm{k}}\right)(\partial k / \partial z)\right)}{\partial z}+\mu_{\mathrm{t}} \Phi-\rho \varepsilon \\
\frac{\partial(\rho k)}{\partial t}+\frac{\partial\left(\rho V_{x} \varepsilon\right)}{\partial x}+\frac{\partial\left(\rho V_{y} \varepsilon\right)}{\partial y}+\frac{\partial\left(\rho V_{z} \varepsilon\right)}{\partial z}= \\
\frac{\partial\left(\left(\mu_{\mathrm{t}} / \sigma_{\varepsilon}\right)(\partial \varepsilon / \partial x)\right)}{\partial x}+\frac{\partial\left(\left(\mu_{\mathrm{t}} / \sigma_{\varepsilon}\right)(\partial \varepsilon / \partial y)\right)}{\partial y} \\
+\frac{\partial\left(\left(\mu_{\mathrm{t}} / \sigma_{\varepsilon}\right)(\partial \varepsilon / \partial z)\right)}{\partial z}+\mu_{\mathrm{t}} \frac{\varepsilon}{k} \Phi-C_{2} \frac{\rho \varepsilon^{2}}{k}
\end{gathered}
$$

where $\mathrm{k}$ is the turbulent kinetic energy and $\varepsilon$ is the turbulent kinetic energy dissipation ratio. $V_{x}, V_{y}$ and $V_{z}$ represent the $x$, $y$ and $z$ components of the velocity $V . \mu_{t}$ is the turbulent viscosity and $\rho$ represents the fluid density, $v$ is the kinematic viscosity, $\Phi$ is the pressure strain, $C_{2}, C_{\mu}, \sigma_{\varepsilon}$ and $\sigma_{k}$ are model constants, $1.92,0.09,1.30$ and 1.00 , respectively.

It was set a turbulence intensity of $1.0 \%$ and a turbulence scale of $0.10 \mathrm{~m}$. Water temperature was set at $28^{\circ} \mathrm{C}$, with a density of $998.2 \mathrm{~kg} \cdot \mathrm{m}^{-3}$, viscosity of $0.001 \mathrm{~kg} \cdot(\mathrm{m} \cdot \mathrm{s})^{-1}$ and an incompressible flow.

Total drag force, total drag coefficient, friction drag and pressure drag were computed at 1.3, 1.5, 1.7, 2.0, 2.2 and $2.5 \mathrm{~m} \cdot \mathrm{s}^{-1}$. This range is representative of elite swimmers' speed gliding after a push-off on the end wall (Barbosa et al., 2013; Lyttle, Blanksby, Elliott, \& Lloyd, 1999).

\section{Analytical procedure}

A set of analytical procedures to assess human hydrodynamics was selected concurrently. The friction drag coefficient was determined by the ITTC-1957 correlation line:

$$
C_{D_{\mathrm{f}}}=\frac{0.075}{(\log (R e)-2)^{2}}
$$

where $R e$ is the Reynolds number of the body and calculated as follows:

$$
R e=\frac{v \times L}{u}
$$

where $v$ is the gliding velocity at the selected speeds $(1.3,1.5$, $1.7,2.0,2.2$ and $\left.2.5 \mathrm{~m} \cdot \mathrm{s}^{-1}\right), L$ is the body length and $v$ is the water kinematic viscosity (being $8.97 \times 10^{-7} \mathrm{~m}^{2} \cdot \mathrm{s}^{-1}$ at $26^{\circ} \mathrm{C}$ ). Beforehand, a set of correlation lines has been compared to learn which one would be used to compute the friction drag coefficient. These included the ITTC-1957, as well as the formulae by Telfer, Prandtl-Schlichting, Schultz-Grunow, KempfKarman, Landweber, Hughes, Wieghardt, Gadd and Prandtl [i.e., "one seventh law" for two different conditions: (1) being $c=0.0576$ and (2) $c=0.0592$ ]. The intra-class correlation (for absolute agreement) between the friction drag component (in $\mathrm{N})$ by the CFD and the analytical model inputting the $C_{D_{\mathrm{f}}}$ by 
the ITTC-1957 was ICC $=0.987$, Telfer's formulae ICC $=0.974$, PrandtI-Schlichting ICC $=0.986$, Schultz-Grunow ICC $=0.986$, Kempf-Karman ICC $=0.986$, Landweber ICC $=0.982$, Hughes ICC $=0.946$, Wieghardt ICC $=0.968$, Gadd ICC $=0.975$, PrandtI (if $c=0.0576$ ) ICC $=0.802$ and Prandtl (if $c=0.0592$ ) ICC $=0.834$. Hence, the ITTC-1957 showed the best goodness-of-fit of all correlation lines selected. Previous researchers also reported a very good approximation by this correlation line but did not share the benchmark against other formulae (Barbosa et al., 2015; Molland, Turnock, \& Hudson, 2011).

The wetted surface area of the body was determined by the Du Bois formulae (Du Bois \& Du Bois, 1916):

$$
A_{\text {wetted }}=0.20247 \times L^{0.725} \times \mathrm{BM}^{0.425}
$$

where $L$ is the participant's body length $(m)$ and BM is the body mass $(\mathrm{kg})$. The friction drag was computed as

$$
D_{f}=0.5 \times \rho \times v^{2} \times A_{\text {wetted }} \times C_{D_{f}}
$$

where $\rho$ is the density of the water (being $998.2 \mathrm{~kg} \cdot \mathrm{m}^{-3}$ ), $v$ is the gliding velocity at the selected speeds, $A_{\text {wetted }}$ is the wetted surface area and $C_{D_{f}}$ is the friction drag coefficient. Pressure drag was calculated as

$$
D_{\mathrm{pr}}=0.5 \times \rho \times v^{2} \times S \times C_{D_{\mathrm{pr}}}
$$

where $\rho$ and $v$ represent the same quantities as in Equation 8, $S$ is the trunk transverse surface area obtained from photogrammetry and $C_{D_{\mathrm{pr}}}$ is the pressure drag coefficient. To measure the $S$, the participant was photographed (DSC-T7, Sony, Tokyo, Japan) on land in the upright and streamlined position in the transverse plane. The area was measured by a dedicated software (UD Ruler, AVPSoft, USA) (ICC $=0.98$ ). This research aims to assess the relationship between numerical simulations and analytical procedures. Hence, an alternative would be to input the $C_{D_{\mathrm{pr}}}$ reported in experimental studies. However, currently, this is not feasible and such data have not yet been reported in the literature. Hence, it was selected a $C_{D_{\mathrm{pr}}}$ of 0.55 . This value is a good approximation of what is reported at similar Reynolds number of the participant recruited for an ellipse (Munson, Young, \& Okiishi, 1990). Total passive drag $\left(D_{\mathrm{f}}\right.$ $\left.{ }_{+p r}\right)$ is the sum of $D_{\mathrm{f}}$ and $D_{\mathrm{pr}}$.

\section{Statistical analysis}

Mean \pm SD were reported for all selected variables. Differences between procedures and partial contribution of $D_{\mathrm{pr}}$ and $D_{\mathrm{f}}$ to $D_{\mathrm{f}+\mathrm{pr}}$ were reported in percentages.
Simple linear regression models between CFD and analytical procedure were computed for SI units (i.e., untransformed units) and after logarithmic transformation setting the limits of agreement at $95 \%$. The plotting after log-log transformation aimed to identify whether the linearity of the phenomenon that was assessed could be enhanced. Trendline equation, determination coefficient $\left(R^{2}\right)$, adjusted determination coefficient $\left(R_{\mathrm{a}}^{2}\right)$ and standard error of estimation (SEE) were reported. Scattergrams feature the trendline and the limits for conventional 95\% confidence intervals (Cls). As far as the partial contribution of each drag component to total drag, it was computed the bootstrap confidence for a 95\% agreement. Effect sizes were set as very weak if $R^{2}<0.04$, weak if $0.04 \leq R^{2}<0.16$, moderate if $0.16 \leq R^{2}<0.49$, high if $0.49 \leq R^{2}<0.81$ and very high if $0.81 \leq R^{2}<1.0$ (Barbosa et al., 2015).

Bland-Altman analysis features the plotting of the mean value of both procedures to highlighted differences between methods. The limits of agreement were set at $95 \% \mathrm{Cl}$ (i.e., \pm 1.96 standard deviations of the difference between procedures).

\section{Results}

The swimmer was $1.90 \mathrm{~m}$ tall and $2.40 \mathrm{~m}$ in the streamlined position (fingertips to feet in the plantar flexion) and $78.32 \mathrm{~kg}$ of body mass. The trunk transverse surface area was measured as being $0.0831 \mathrm{~m}^{2}$ by the CT scan and $0.0828 \mathrm{~m}^{2}$ by the photogrammetric technique.

The area $\times C_{D_{f}}$ relationship for CFD versus ITTC-1957 was $R^{2}=0.81(P=0.02)$ ranging the values between $0.0101-0.0074$ and $0.0089-0.0079 \mathrm{~m}^{2}$, respectively. The absolute differences in the area $\times C_{D_{\mathrm{f}}}$ between procedures ranged between 0.0001 and $0.0013 \mathrm{~m}^{2}$. Hence, the ITTC-1957 showed a very good approximation to data obtained by CFD.

The $D_{f+p r}$ ranged between 45.44 and $144.06 \mathrm{~N}$ in the numerical simulation, 46.03 and $167.06 \mathrm{~N}$ in the analytical procedure (Table 1, Figure 1). The $C_{D}$ ranged between 0.698 and 0.622 by the numerical simulation, 0.657 and 0.644 by the analytical procedure (Table 1, Figure 1). Overall, there was a trend for an overestimation by the analytical procedure with increasing drift as a function of speed (Figure 1).

The linear regression models between CFD and analytical procedure showed a very high adjustment for the $D_{\mathrm{f}+\mathrm{pr}}$ (SI units: $R^{2}=0.98, P<0.001$; log transformation: $R^{2}=0.99$, $P<0.001$ ) (Figure 2, panels $A$ and $C$ ). The $C_{D}$ also obtained a very high adjustment (SI units: $R^{2}=0.97, P<0.001$; log transformation: $R^{2}=0.97, P<0.001$ ) (Figure 2 , panels $\mathrm{B}$ and

\begin{tabular}{|c|c|c|c|c|c|c|c|c|c|c|}
\hline \multirow[b]{2}{*}{ Velocity $\left[\mathrm{m} \cdot \mathrm{s}^{-1}\right]$} & \multicolumn{2}{|c|}{$D_{\mathrm{f}+\mathrm{pr}}[\mathrm{N}]$} & \multicolumn{2}{|c|}{$C_{D}$ [dimensionless $]$} & \multicolumn{2}{|c|}{$D_{\mathrm{f}}[\mathrm{N}]$} & \multicolumn{2}{|c|}{$D_{\mathrm{pr}}[\mathrm{N}]$} & \multicolumn{2}{|c|}{$\% D_{\mathrm{pr}}$} \\
\hline & Anal. & CFD & Anal. & CFD & Anal. & CFD & Anal. & CFD & Anal. & CFD \\
\hline 1.3 & 46.03 & 45.44 & 0.657 & 0.698 & 7.48 & 8.55 & 38.55 & 36.89 & 83.76 & 81.18 \\
\hline 1.5 & 61.01 & 56.51 & 0.654 & 0.678 & 9.69 & 9.8 & 51.33 & 46.71 & 84.12 & 82.66 \\
\hline 2.0 & 107.57 & 94.21 & 0.648 & 0.636 & 16.32 & 15.88 & 91.25 & 78.33 & 84.83 & 83.14 \\
\hline 2.2 & 129.82 & 122.87 & 0.647 & 0.628 & 19.41 & 20.36 & 110.41 & 102.51 & 85.05 & 83.43 \\
\hline 2.5 & 167.06 & 144.06 & 0.644 & 0.622 & 24.49 & 23.01 & 142.57 & 121.05 & 85.34 & 84.03 \\
\hline
\end{tabular}

Table 1. The comparison of the hydrodynamic outputs between numerical simulation (CFD) and analytical procedure (Anal.) for the total drag ( $\left.D_{f+p r}\right)$, drag coefficient $\left(C_{\mathrm{D}}\right)$, friction drag $\left(D_{\mathrm{f}}\right)$, pressure drag $\left(D_{\mathrm{pr}}\right)$ and partial contribution of the pressure drag to total drag $\left(\% D_{\mathrm{pr}}\right)$. 


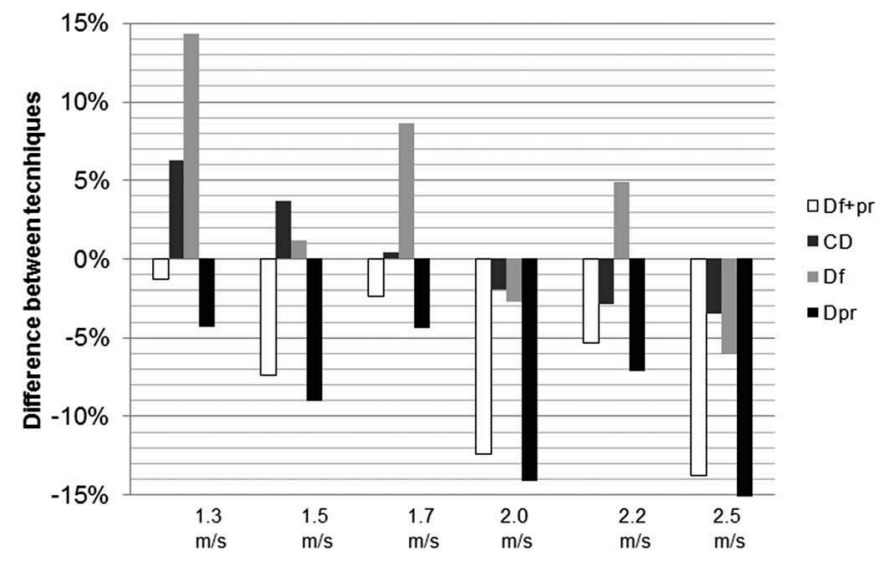

Figure 1. Partial difference between numerical simulation and analytical procedure for the total drag $\left(D_{f+p r}\right)$, drag coefficient $\left(C_{D}\right)$, friction drag $\left(D_{f}\right)$ and pressure drag $\left(D_{\mathrm{pr}}\right)$. Negative values represent an overestimation by the analytical procedure.

D). The $95 \% \mathrm{Cl}$ for the slope of the correlation line $(\beta)$ ranged between: (1) 1.007-1.360 for the $D_{f+p r}$ in SI units; (2) 0.9501.210 for the $D_{\mathrm{f}+\mathrm{pr}}$ after log-transformation; (3) 0.121-0.190 for the $C_{D}$ in SI units and (4) $0.124-0.0190$ for the $C_{D}$ after logtransformation.

The Bland-Altman analysis revealed that the difference for the $D_{\mathrm{f}+\mathrm{pr}}$ was $8.37 \mathrm{~N}(95 \% \mathrm{Cl}:-8.57 ; 25.32)$ and $0.076(95 \% \mathrm{Cl}$ : -0.033; 0.186) after logarithmic transformation (Figure 2, panels $A$ and $C$ ). The $C_{D}$ bias was -0.0033 (95\% Cl: -0.054 ; $0.048)$ when reported in $\mathrm{SI}$ units and also $-0.0033(95 \% \mathrm{Cl}$ : $-0.076 ; 0.070$ ) for the log-log plot (Figure 2, panels $B$ and $D$ ). In the latter case, there was an overlap of two plots in the coordinate $[-0.455 ; 0.03]$. All points were within the $\mathrm{Cl}$.
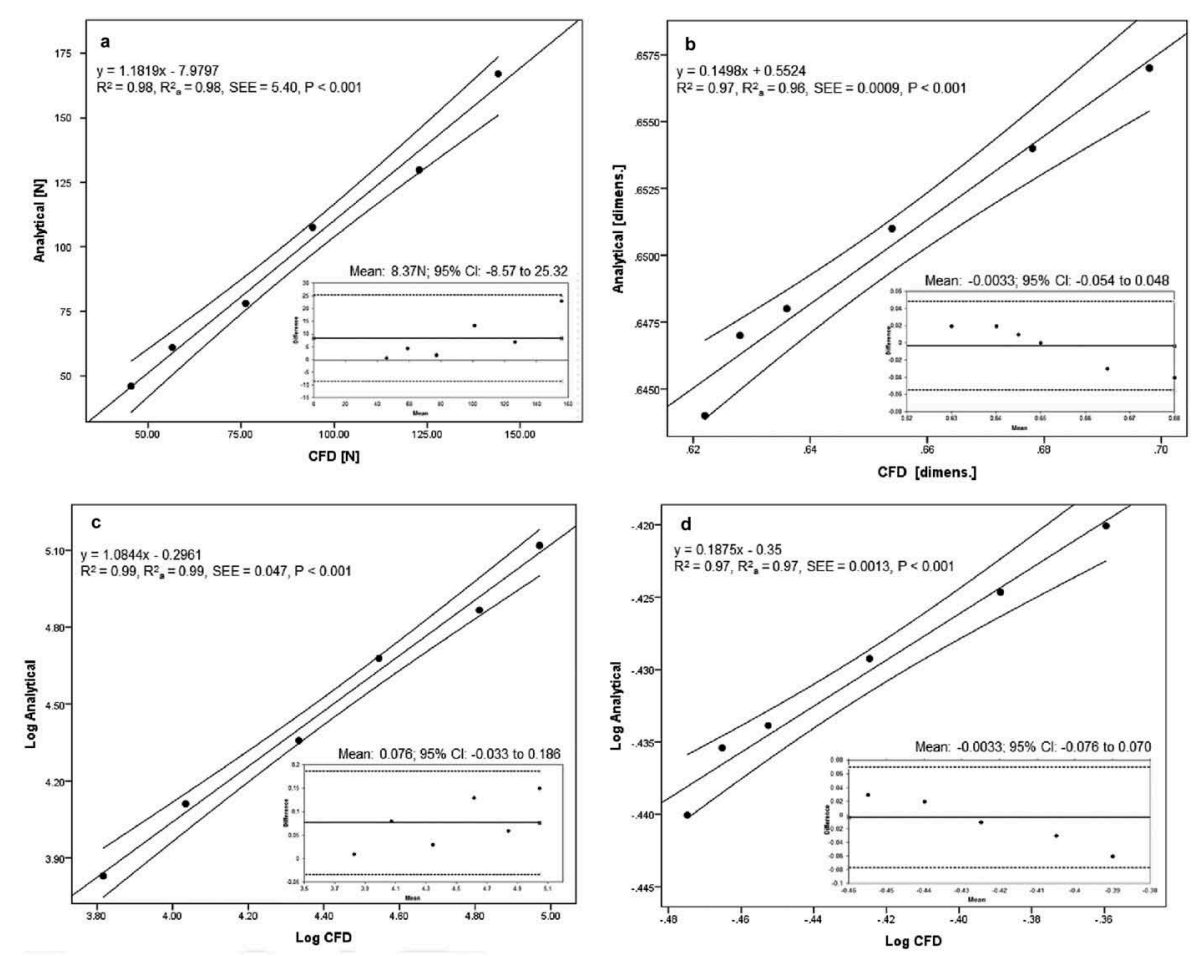

\section{Discussion}

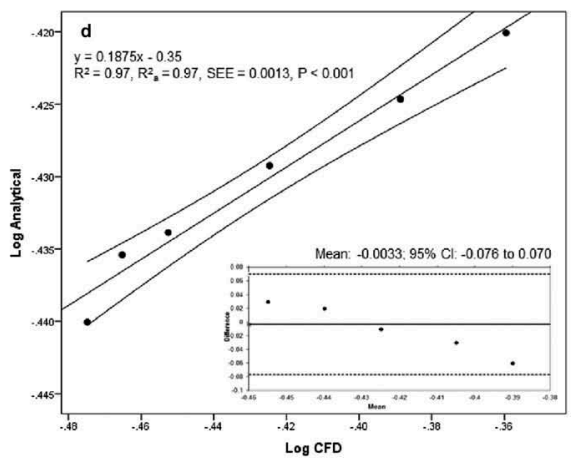

The $D_{\mathrm{pr}}$ represented $81.18-83.43 \%$ of the $D_{\mathrm{f}+\mathrm{pr}}$ with the numerical simulation, $83.76-85.34 \%$ with the analytical procedure (Table 1). The $D_{f}$ represented the remaining 15.97$18.82 \%$ of the $D_{f+p r}$ by the numerical simulation, $14.66-$ $16.21 \%$ by the analytical procedure. With increasing speed, it was possible to verify the trade-off between $D_{\mathrm{f}}$ and $D_{\mathrm{pr}}$ (Figure 3). Yet, $D_{\mathrm{pr}}$ was the main determinant to total drag at this speed range.

Due to the nature of hydrodynamic testing and small sample size, the researches were concerned with the external validity of these findings. They computed the bootstrap $\mathrm{Cl}$ for a $95 \%$ agreement that were (1) $14.99-15.85 \%$ for $D_{f}$ by analytical procedure, (2) $84.14-85.00 \%$ for $D_{\mathrm{pr}}$ by analytical procedure, (3) $16.52-17.87 \%$ for $D_{f}$ by CFD and (4) $82.06-$ $83.48 \%$ for $D_{\mathrm{pr}}$ by CFD.

The aim was to compare the passive drag-gliding underwater by a numerical simulation and an analytical procedure. There was a strong relationship between modelling techniques although showing an overestimation by the analytical procedure. The partial contribution of $D_{\mathrm{pr}}$ and $D_{\mathrm{f}}-D_{\mathrm{f}+\mathrm{pr}}$ was about $85-15 \%$ by both modelling techniques.

The goodness-of-fit of the analytical model is sensitive to the inputted data. There are several devices that can be selected to assess the swim speed, with different levels of accuracy, e.g., stopwatches (Craig \& Pendeegast, 1979), speedo-meters (Barbosa et al., 2013), motion-capture systems (Figueiredo, Barbosa, Vilas-Boas, \& Fernandes, 2012), radar or laser beam (Hochstein \& Blickhan, 2011) and inertial measurement units (Dadashi et al., 2013). The trunk transverse surface

Figure 2. Relationship between numerical simulation and analytical procedure assessing the total drag (panels A and C), and the drag coefficient (panels B and C) in SI unit and after logarithmic transformation, respectively. 

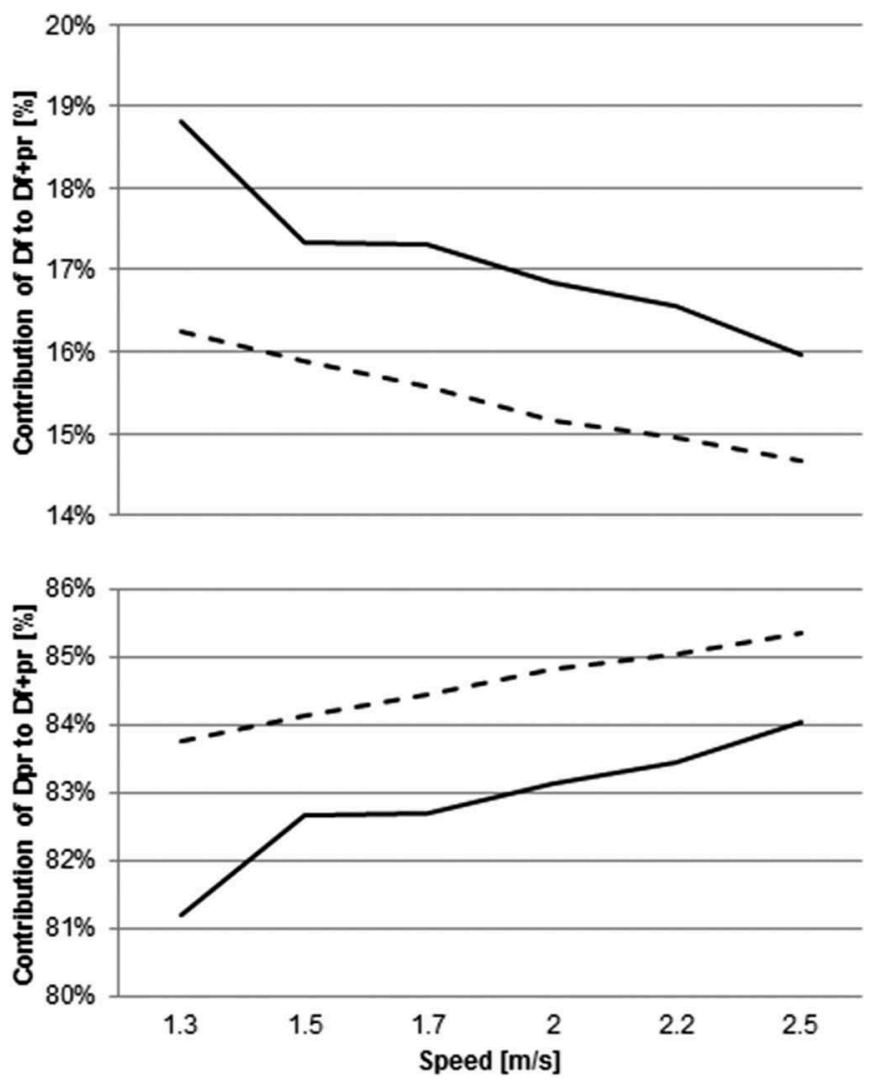

Figure 3. Changes in the partial contribution of the friction drag $\left(D_{f}\right)$ and pressure drag $\left(D_{\mathrm{pr}}\right)$ to total drag $\left(D_{\mathrm{f}+\mathrm{pr}}\right)$ when assessed by numerical simulation (solid line) and analytical procedure (dash line).

area assessed by photogrammetry provides accurate data, when benchmarked with $C T$ scans. Having said that, the $C T$ scan or any other procedure providing a 3D body scan should be considered as the gold-standard in comparison to a $2 \mathrm{D}$ photogrammetric technique; despite under some circumstances (e.g., testing a large number of participants), the latter option may be more feasible. Hence, one first source of bias between the analytical model employed and the CFD simulation might be that different procedures have been selected to assess the anthropometrics and inertial proprieties. Practically, scientists are unable to collect anthropometrics and inertial parameters by cutting-edge devices such as CT scans or 3D body scans. Alternatively, they can select a photogrammetric technique. This method requires a digital camera and an image editing software. Therefore, researchers aimed to understand if this straightforward procedure would be reliable and insightful enough in comparison to gold-standard procedures. According to our research results, the photogrammetric technique is indeed a feasible option. Nevertheless, CT scan and $3 \mathrm{D}$ body scan should be considered as top priority whenever possible. Another interesting option is the measurement frame-by-frame of the in-water frontal surface area by photogrammetry of a video (i.e., intra-cyclic fluctuations of the frontal area) (Gatta, Cortesi, Fantozzi, \& Zamparo, 2015).

Experimental testing, it is the mainstream procedure to assess the hydrodynamics in competitive swimming. However, there are some advantages selecting numerical simulations and analytical procedures. Experimental testing will involve the data collection over several trials by a swimmer and in a research project by a reasonable number of swimmers. This set of trials aims to minimise as much as possible the within- and if feasible the between-subjects variability (Seifert et al., 2014). Gliding the participant will have small adjustments of the limbs, head and body trying to displace farther and keep the equilibrium. On the other hand, by running numerical simulations and employing analytical procedures, this variability is not a true concern. If the aim of the research is to assess the variability in the gliding performance, the latter techniques (CFD and analytical procedures) are not the best options and an experimental test should be selected.

Another factor to consider is the selection of the best correlation line to estimate the friction drag coefficient. Researchers have previously tested a set of correlation lines described as suitable for the range $10^{5}<R e<10^{7}$ (typical number for humans and small vessels) and $10^{7}<R e<10^{9}$ (typical of big vessels) (refer the Methods section - analytic procedures). It was expected that a correlation line within the Re reported for humans should return the best adjustment. However, the ITTC-1957 correlation line showed a better adjustment than other friction correlation lines. The same phenomenon was reported earlier for 60 young swimmers (Barbosa et al., 2015). The ICC between the friction drag component by CFD and the ITTC-1957 was 0.987 . It was slightly better than other options such as the Prandtl-Schilichting, the Schultz-Grunow or the Kempf-Karman skin-friction equations. It was unclear why correlation lines modelled for higher Re showed a better adjustment. One may claim that these equations encompass the logarithmic number of the $R e$, whereas the vast majority of the correlation lines for lower $R e$ are exponential equations. Indeed, an exponential function is the inverse of a logarithmic function. The latter approach may show a better approximation to what happens on a human body. In the near future, it would be interesting to report a skin-friction correlation line dedicated to human bodies.

The challenge seems to be the selection of the input value of the pressure drag coefficient. Selecting the $C_{D_{\mathrm{pr}}}$ from a CFD analysis and inputting this in the analytical model would encompass a circular reasoning. Unfortunately, past experimental studies do not report the $C_{D_{\mathrm{pr}}}$. Therefore, we input the value for an ellipse. It should be acknowledged that there are some limitations in this selection. An ellipse does not represent perfectly the geometry of the trunk transverse area. Nevertheless, this reasoning has been used in the past in biomechanics to provide the inertial parameters of human bodies on land and in the air (Yeadon, 1990). Selecting only the analytical procedure, the researcher or practitioner can run a CFD analysis beforehand to retrieve the $C_{D_{\mathrm{pr}}}$. For instance, if practitioners aim to monitor the swimmer's hydrodynamics over a race, they can run a numerical simulation on the athlete before the event to retrieve the $C_{D_{\mathrm{pr}}}$. These data can be inputted into the analytical model to improve the accuracy of the measurements. If this is not feasible, alternatively they should consider inserting the value reported for a plate or ellipse at the participant's Reynolds number, but being aware of the potential bias. 
One assumption of our research was that the body was gliding at an angle of attack of zero degrees. That is, the swimmer is gliding horizontally and fully immersed. However, the angle of attack is different from zero in the water entry after the start and the water breakout after the start or a turn (Vantorre, Chollet, \& Seifert, 2014). That is, the body is in an oblique position. In such events, to ensure accuracy, it is necessary to perform a correction in the trunk transverse surface area (Equation 9) estimating the $D_{\mathrm{pr}}$. This correction encompasses the trigonometric calculation of the projected frontal surface area (Mollendorf et al., 2004):

$$
\mathrm{PSA}=S \times \cos a+\frac{\mathrm{BSA}}{2} \times \sin a
$$

where PSA represents the projected frontal surface area, $S$ is the trunk transverse surface area, BSA is the body surface area (that can be estimated by Dubois and Dubois formulae) and $a$ is the angle of attack. The angle of attack can be obtained measuring the trunk inclination (Zamparo, Gatta, Pendergast, \& Capelli, 2009).

Vilas-Boas et al. (2010) noted a gliding speed in breaststroke of $1.37 \mathrm{~m} \cdot \mathrm{s}^{-1}$ after the push-off in national level swimmers. Costa et al. (2015) assessed the push-off at speeds between 1.1 and $1.7 \mathrm{~m} \cdot \mathrm{s}^{-1}$. Shahbazi, Sanders, McCabe and Adams (2007) reported that experienced swimmers show a speed after the tumble turn of $2.42 \mathrm{~m} \cdot \mathrm{s}^{-1}$. Hence, it seems that the vast majority of the swimmers may reach a speed within the range selected by the researchers of this study (from 1.3 to $2.5 \mathrm{~m} \cdot \mathrm{s}^{-1}$ ). Only some extreme cases might go beyond the $2.5 \mathrm{~m} \cdot \mathrm{s}^{-1}$ and one may claim that those are peak velocities (i.e., instantaneous and not mean velocities). Having assessed the hydrodynamics up to $2.5 \mathrm{~m} \cdot \mathrm{s}^{-1}$, an extrapolation at $3.0 \mathrm{~m} \cdot \mathrm{s}^{-1}$ was conducted to tackle one's concern. When the data reported in Table 1 were extrapolated to $3.0 \mathrm{~m} \cdot \mathrm{s}^{-1}$, the total drag was $239 \mathrm{~N}$ for the analytical procedure and $205 \mathrm{~N}$ for the CFD (difference between methods was $14.4 \%$ ). It was an increase by only $0.7 \%$ in the bias reported at $2.5 \mathrm{~m} \cdot \mathrm{s}^{-1}$ (Figure 1). Hence, data are still reasonably reliable at $3.0 \mathrm{~m} \cdot \mathrm{s}^{-1}$.

The range of values for $D_{\mathrm{f}+\mathrm{pr}}$ (Table 1) was within values reported by previous experimental studies (Clarys, 1979; Lyttle, Blanksby, Elliott, \& Lloyd, 1998; Miyashita \& Tsunoda, 1978). Using experimental techniques, it was noted that male national level swimmers showed $51.9 \mathrm{~N}$ (Clarys, 1979), and female swimmers $35.5 \mathrm{~N}$ of mean drag force (Miyashita \& Tsunoda, 1978). Male swimmers travelling at $1.6 \mathrm{~m} \cdot \mathrm{s}^{-1}$ experienced a drag force of $58.1 \mathrm{~N}$ (Lyttle et al., 1998) when measured by a towing test (i.e., experimental technique). An interpolation of these data showed that $D_{f+p r}$ was 69.3 and $65.7 \mathrm{~N}$ by the analytical procedure and CFD simulation, respectively. The differences can be explained by the variability in the anthropometric features of the participants recruited in both studies. Comparing our data with CFD papers available, data by Bixler et al. (2007) were lower $\left(31.58-70.08 \mathrm{~N}\right.$ at $\left.1.5-2.25 \mathrm{~m} \cdot \mathrm{s}^{-1}\right)$ but showing a good adherence to Marinho et al. (2011) results. However, it was found an overestimation by the analytical procedure that tends to increase with speed (Figure 1). This bias can be explained by the different inputs in the analytical procedure and the CFD as discussed previously. The $D_{f+p r}$ bias was up to $7 \%$ in the $1.3-1.7 \mathrm{~m} \cdot \mathrm{s}^{-1}$ band and up to $14 \%$ in the $2.0-$ $2.5 \mathrm{~m} \cdot \mathrm{s}^{-1}$ band. The $D_{\mathrm{f}+\mathrm{pr}}$ and $D_{\mathrm{pr}}$ drifts were coupled. Hence, the source of the bias might have been the different behaviour of the pressure drag coefficient with speed of an elliptical plate and a human body.

Linear regression models between procedures depicted very high adjustments (Figure 2). It is less challenging to verify high adjustments when the range of speeds selected is reasonably wide. The goodness-of-fit of our data was higher than what was noted for the comparison of experimental testing with CFD $\left(D_{\mathrm{f}+\mathrm{pr}}: R^{2}=0.90 ; C_{\mathrm{D}}: R^{2}=0.86\right)$ (Costa et al., 2015) and analytical procedure ( $D_{\mathrm{f}+\mathrm{pr}}$ : $R^{2}=0.90 ; C_{\mathrm{D}}: R^{2}=0.96$ ) (Barbosa et al., 2015). The BlandAltman analysis revealed that all plots were within the agreement limits. In this circumstance, it was more interesting the discussion of the SEE and the $95 \% \mathrm{Cl}$ of the $\beta$. The SEEs are quite reasonable for the ranges assessed. The $\beta$ showed that each unit of increase by the CFD leads to an increase by the analytical procedure of 1.007-1.360 units in the $D_{\mathrm{f}+\mathrm{pr}}$ (reflecting the overestimation reported earlier). However, to tackle this concern, the adjustment was improved after log-log transformation because the $95 \% \mathrm{Cl}$ was narrowed to $0.950-1.210$, shifting to the left side, i.e., being more centred (or close) to 1.0.

The partial contribution of $D_{\mathrm{f}}$ and $D_{\mathrm{pr}}$ to $D_{\mathrm{f}+\mathrm{pr}}$ was about $15-85 \%$ for both techniques, despite there was a trade-off between components with increasing speed (Table 1, Figure 3). As speed increases, so does the partial contribution of the $D_{\mathrm{pr}}$. One of the first papers on this topic selecting analytical procedures reported a lower contribution by the $D_{\mathrm{pr}}$ (Mollendorf et al., 2004). The aim of this paper was to assess the effect of different swimsuits (Mollendorf et al., 2004). Indeed, there is evidence that different swimsuit models impose significant changes in the pressure and friction components (Mollendorf et al., 2004). Data on the partial contribution by each drag component presented similar results with recent paper by Barbosa et al. (2015) which also reported a $15-85 \%$ relationship between $D_{f}$ and $D_{p r}$ in young swimmers. The reason for the mixed findings can be related to as follows: (1) the assumptions of the two models were different; (2) the data were collected differently or (3) the aims of both studies differed.

\section{Conclusion}

As a conclusion, there was a strong relationship between the $D_{\mathrm{f}+\mathrm{pr}}$ and $C_{\mathrm{D}}$ assessed by CFD and the analytical procedure. However, an overestimation of the outputs by the analytical procedure was verified. The $D_{\mathrm{pr}}-D_{\mathrm{f}}$ partial contribution was about $85-15 \%$. Therefore, despite the bias, the analytical procedure offers a feasible way to gather some insight on one's hydrodynamics. This procedure may provide insight on the hydrodynamics of a swimmer during phases of a race. Therefore, it is a reliable procedure to monitor the swimmer's hydrodynamics on regular basis, such as for instance, in training or competition settings. 


\section{Acknowledgements}

This project was supported by national funds granted by the Portuguese Science and Technology Foundation (FCT) (UID/DTP/04045/2013) and European Union fund for regional development (FEDER) under the COMPETE 2020 Programme for Competitiveness and internationalization (POCl) (POCl-01-0145-FEDER-006969).

\section{Disclosure statement}

No potential conflict of interest was reported by the authors.

\section{Funding}

This project was supported by national funds granted by the Portuguese Science and Technology Foundation (FCT) [Grant Number UID/DTP/04045/ 2013] and European Union fund for regional development (FEDER) under the COMPETE 2020 Programme for Competitiveness and internationalization (POCI) [POCI-01-0145-FEDER-006969].

\section{References}

Barbosa, T. M., Bragada, J. A., Reis, V. M., Marinho, D. A., Carvalho, C., \& Silva, A. J. (2010). Energetics and biomechanics as determining factors of swimming performance: Updating the state of the art. Journal of Science and Medicine in Sport, 13(2), 262-269. doi:10.1016/j. jsams.2009.01.003

Barbosa, T. M., Costa, M. J., Morais, J. E., Morouço, P., Moreira, M., Garrido, N. D., ... Silva, A. J. (2013). Characterization of speed fluctuation and drag force in young swimmers: A gender comparison. Human Movement Science, 32(6), 1214-1225. doi:10.1016/j.humov.2012.07.009

Barbosa, T. M., Morais, J. E., Forte, P., Neiva, H., Garrido, N. D., \& Marinho, D. A. (2015). A comparison of experimental and analytical procedures to measure passive drag in human swimming. PLoS One, 10(7), e0130868. doi:10.1371/journal.pone.0130868

Bixler, B., Pease, D., \& Fairhurst, F. (2007). The accuracy of computational fluid dynamics analysis of the passive drag of a male swimmer. Sports Biomechanics, 6(1), 81-98. doi:10.1080/14763140601058581

Clarys, J. (1979). Human morphology and hydrodynamics. In J. Terauds (Ed.), Swimming science III (pp. 3-41). Baltimore, MD: University Park Press.

Costa, L., Mantha, V. R., Silva, A. J., Fernandes, R. J., Marinho, D. A., VilasBoas, J. P., ... Rouboa, A. (2015). Computational fluid dynamics vs. inverse dynamics methods to determine passive drag in two breaststroke glide positions. Journal of Biomechanics, 48(10), 2221-2226. doi:10.1016/j.jbiomech.2015.03.005

Craig, A. B., \& Pendeegast, D. R. (1979). Relationships of stroke rate, distance per stroke, and velocity in competitive swimming. Medicine \& Science in Sports \& Exercise, 11(3), 278-283. doi:10.1249/00005768197901130-00011

Dadashi, F., Crettenand, F., Millet, G. P., Seifert, L., Komar, J., \& Aminian, K. (2013). Automatic front-crawl temporal phase detection using adaptive filtering of inertial signals. Journal of Sports Sciences, 31(11), 1251-1260. doi:10.1080/02640414.2013.778420

Du Bois, D., \& Du Bois, E. F. (1916). A formula to estimate the approximate surface area if height and weight be known. Archives of Internal Medicine, 17, 863-871. doi:10.1001/archinte.1916.00080130010002

Figueiredo, P., Barbosa, T. M., Vilas-Boas, J. P., \& Fernandes, R. J. (2012). Energy cost and body centre of mass' 3D intracycle velocity variation in swimming. European Journal of Applied Physiology, 112(9), 3319-3326. doi:10.1007/s00421-011-2284-6

Formosa, D. P., Sayers, M. G., \& Burkett, B. (2014). Quantifying stroke coordination during the breathing action in front-crawl swimming using an instantaneous net drag force profile. Journal of Sports Sciences, 32(18), 1729-1737. doi:10.1080/02640414.2014.915424

Gatta, G., Cortesi, M., Fantozzi, S., \& Zamparo, P. (2015). Planimetric frontal area in the four swimming strokes: Implications for drag, energetics and speed. Human Movement Science, 39, 41-54. doi:10.1016/j. humov.2014.06.010

Hochstein, S., \& Blickhan, R. (2011). Vortex re-capturing and kinematics in human underwater undulatory swimming. Human Movement Science, 30(5), 998-1007. doi:10.1016/j.humov.2010.07.002

Kjendlie, P.-L., \& Stallman, R. K. (2008). Drag characteristics of competitive swimming children and adults. Journal of Applied Biomechanics, 24, 3542. doi:10.1123/jab.24.1.35

Lyttle, A., Blanksby, B., Elliott, B., \& Lloyd, D. (1999). Optimal depth for streamlined gliding. In K. Keskinen, P. Komi, \& P. Hollander (Eds.) Biomechanics and medicine in swimming VIII (pp. 165-170). Jyvaskyla: Gummerus Printing.

Lyttle, A. D., Blanksby, B. A., Elliott, B. C., \& Lloyd, D. G. (1998). The effect of depth and velocity on drag during the streamlined glide. Journal of Swimming Research, 13, 15-22.

Marinho, D., Barbosa, T. M., Rouboa, A., \& Silva, A. (2011). The hydrodynamic study of the swimming gliding: A two-dimensional computational fluid dynamics (CFD) analysis. Journal of Human Kinetics, 29, 4957. doi:10.2478/v10078-011-0039-4

Miyashita, M., \& Tsunoda, T. (1978). Water resistance in relation to body size. In J. Terauds \& E. W. Beringfield (Eds.), Swimming medicine III (pp. 395-401). Baltimore, MD: University Park Press.

Molland, A. F., Turnock, S. R., \& Hudson, D. A. (2011). Ship resistance and propulsion: Practical estimation of ship propulsive power. Cambridge: Cambridge University Press.

Mollendorf, J. C., Termin, A. C., Oppenheim, E. R. I. C., \& Pendergast, D. R. (2004). Effect of swim suit design on passive drag. Medicine \& Science in Sports \& Exercise, 36(6), 1029-1035. doi:10.1249/01.MSS.0000128179.02306.57

Munson, B. R., Young, D. F., \& Okiishi, T. H. (1990). Fundamentals of fluid mechanics. New York, NY: John Wiley \& Sons.

Rouboa, A., Silva, A., Leal, L., Rocha, J., \& Alves, F. (2006). The effect of swimmer's hand/forearm acceleration on propulsive forces generation using computational fluid dynamics. Journal of Biomechanics, 39(7), 1239-1248. doi:10.1016/j.jbiomech.2005.03.012

Seifert, L., Komar, J., Barbosa, T., Toussaint, H., Millet, G., \& Davids, K. (2014). Coordination pattern variability provides functional adaptations to constraints in swimming performance. Sports Medicine, 44(10), 1333-1345. doi:10.1007/s40279-014-0210-x

Shahbazi, M., Sanders, R., McCabe, C., \& Adams, D. (2007). Investigating correlations between swim pike turn kinematics variables in front crawl. In H.-J. Menzel \& M. H. Chagas (Eds), Proceedings XXV symposium of the international society of biomechanics in sports symposium (pp. 381-384). Ouro Preto: Federal University of Minas Gerais.

Takagi, H., Nakashima, M., Sato, Y., Matsuuchi, K., \& Sanders, R. H. (2015). Numerical and experimental investigations of human swimming motions. Journal of Sports Sciences, 23, 1-17.

Vantorre, J., Chollet, D., \& Seifert, L. (2014). Biomechanical analysis of the swim-start: A review. Journal of Sports Science \& Medicine, 13(2), 223.

Vennell, R., Pease, D., \& Wilson, B. (2006). Wave drag on human swimmers. Journal of Biomechanics, 39(4), 664-671. doi:10.1016/j.jbiomech.2005.01.023

Vilas-Boas, J.P, Costa, L, Fernandes, R.J, Ribeiro, J, Figueiredo, P, Marinho, D. A, Silva, A.J, Rouboa, A, \& Machado, L. (2010). Determination of the drag coefficient during the first and second gliding positions of the breaststroke underwater stroke. Journal Of Applied Biomechanics, 26, 324-331. doi:10.1123/jab.26.3.324

Yeadon, M. R. (1990). The simulation of aerial movement-II. A mathematical inertia model of the human body. Journal of Biomechanics, 23(1), 67-74. doi:10.1016/0021-9290(90)90370-I

Zamparo, P., Gatta, G., Pendergast, D., \& Capelli, C. (2009). Active and passive drag: The role of trunk incline. European Journal of Applied Physiology, 106(2), 195-205. doi:10.1007/s00421-009-1007-8 